Trinity College

Trinity College Digital Repository

Faculty Scholarship

2007

The Rise, Decline and Rise of Incomes Policies in the US During

the Post-war Era: An Institutional-analytical Explanation of

Inflation and the Functional Distribution of Income

Mark Setterfield

Trinity College, MARK.SETTERFIELD@TRINCOLL.EDU

Follow this and additional works at: https://digitalrepository.trincoll.edu/facpub

Part of the Economics Commons 


\title{
The rise, decline and rise of incomes policies in the US during the post-war era: an institutional-analytical explanation of inflation and the functional distribution of income
}

\author{
MARK SETTERFIELD* \\ Department of Economics, Trinity College, Hartford, CT and Associate Member Cambridge \\ Centre for Economic and Public Policy, Cambridge University. Email: mark.setterfield@trincoll.edu
}

\begin{abstract}
This paper is based on the premise that at any point in time, macroeconomic performance is best understood in terms of certain 'fundamental' features of the income-generating process that are embedded in a relatively enduring institutional framework, that both affects and is affected by macroeconomic outcomes themselves. This results in the evolution of capitalist economies through a succession of discrete, medium-term episodes of macroeconomic performance. The purpose of the paper is to apply this vision to the explanation of inflation and the functional distribution of income in the post-war US economy. A conflicting claims model of inflation is developed, in which inflation is the result of conflict over the functional distribution of income. It is then shown how an account of the different, relatively enduring institutions within which this 'fundamental' macroeconomic process has been embedded over the past 50 years can be used to calibrate the analytical model, giving rise to an explanation of inflation and the functional distribution of income in the US as having evolved through three discrete episodes. Moreover, once the institutional context of macroeconomic performance is properly recognized in this manner, inflation and the functional distribution of income in the US over the past 50 years are seen to be explained by the rise, decline, and rise of successive incomes policies.
\end{abstract}

\section{Introduction}

During the 1970s and early 1980s, the US economy experienced rates of inflation quite unlike those encountered either before or since. The annual average rate of inflation, which had been $3.1 \%$ for $1960-73$, more than doubled to $7.1 \%$ during the period 1974-89, before falling back to $3.1 \%$ between 1990 and 2000 . The

*Correspondence to: Mark Setterfield, Professor of Economics, Department of Economics, Trinity College, Hartford, CT 06106, USA. Email: mark.setterfield@trincoll.edu

I would like to thank three anonymous referees for their helpful comments on an earlier draft of this paper. Any remaining errors are my own. 
current conventional wisdom is that this pattern of first low, then high, then low inflation during the post-war period is best explained by monetary policy shocks that created a 'great inflation' during the 1970s/1980s. These shocks are attributed either to deliberate policy interventions motivated by the desire to avoid recession in the real economy, or else some form of honest mistake, such as an inability to accurately estimate the natural rate of unemployment, or a failure to obey the 'Taylor principle' when adjusting nominal interest rates in response to changes in expected inflation. ${ }^{1}$

Despite superficial differences, the common core of all variants of the conventional wisdom outlined above is that inflation is exclusively caused by excess aggregate demand in an economy characterized by a unique and stable supply-determined equilibrium rate of unemployment. The thesis advanced in this paper departs radically from this common core, positing that inflation is rooted in conflict over the distribution of income in a demand-determined economy that displays no propensity to gravitate towards any pre-determined (on the supply-side) equilibrium rate of unemployment. Nor is the economy understood to be structurally self-regulating. Specifically, it is held that capitalist economies do not automatically create the institutional structures necessary to permit reconciliation of low rates of inflation with low unemployment and high growth. Rather, at any point in time, the 'fundamental' properties of the inflation process rooted in conflict over the distribution of income are embedded in a historically specific institutional framework. Together, these constitute a macroeconomic regime that, at any point in time, will give rise to conditional equilibrium inflation outcomes. The latter are conditional in the specific sense that they depend on the reproduction over time of the particular institutional framework within which the 'fundamentals' of the inflation process are currently embedded. Since institutions are relatively inert and enduring, the conditional equilibrium inflation rates described above will also endure, becoming part of discrete, medium-run episodes of macroeconomic performance. ${ }^{2}$

But institutions are not immutable - they can, and do, change over time. This change in the institutional structure of the economy will give rise to (inter alia) change in the conditional equilibrium rate of inflation. It is thus institutional change that this paper seeks to associate with the variations in the US inflation

1 See, for example, Collard and Dellas (2004) for a summary and assessment of this conventional wisdom. See also Orphanides and Williams (2004) on the 'natural rate misperception' theory of the great inflation, and Clarida et al. (2000) for discussion of the importance of the Taylor principle for providing a nominal anchor (i.e., a determinate equilibrium rate of inflation) for the economy. The 'honest mistake' hypothesis is currently popular amongst advocates of the new consensus/new neoclassical synthesis macroeconomics (on which see, for example, Clarida et al., 1999).

2 The notion of a medium run is not, as yet, an established feature of most macroeconomic analysis, but evidence strongly suggests that a salient characteristic of contemporary capitalism is discrete phases or episodes of better or worse macroeconomic performance lasting several consecutive business cycles. See, for example, Cornwall and Cornwall (2001). 
rate identified earlier. Specifically, the thesis advanced is that during the post-war period, the inflation experience of the US economy has reflected the rise, decline, and rise of successive incomes policies, where the latter are defined as formal and/or informal institutions that frame and mediate aggregate wage and price setting behaviour in such a way as to reduce conflict over income shares and better reconcile conflicting income claims. ${ }^{3}$ Conventional wisdom would have it that incomes policies experienced only a brief - and unsuccessful - trial as an anti-inflation device during the early 1970s. ${ }^{4}$ But the argument developed here is that the two low inflation episodes during recent US macroeconomic history correspond precisely to the operation of two successful (in terms of their capacity to reduce inflation) but structurally very different incomes policies, with the high inflation interlude during the 1970s and 1980s - including the period that conventional wisdom identifies with the brief and unsuccessful adoption of incomes policies - constituting an inter-regnum.

In order to develop this argument more fully, the remainder of the paper is organized as follows. Section 2 briefly discusses the methodology on which the paper is based. Section 3 then constructs a conflicting-claims model of inflation that is consistent with the 'fundamentals' of the inflation process identified in Section 2. In Section 4, the conflicting claims model is 'calibrated' on the basis of both quantitative and qualitative information about the successive (and different) institutional frameworks within which it has been embedded over the past half century. It is shown that the conditional equilibrium outcomes of the resulting model can be used to successfully explain the evolution of inflation and the wage share of income in the US over three successive episodes of macroeconomic performance (1960-73, 1974-89, and 1990-2000) and that this, in turn, substantiates the claim that the post-war US economy has been characterized by the rise, decline, and rise of successive incomes policies. Finally, Section 5 offers some conclusions.

3 It is important to note that this definition of incomes policies is broader than that conventionally adopted, in which incomes policies are identified exclusively with formal institutions (i.e., laws - see, for example, Hunt, 2002). The definition above does not preclude formal institutions from contributing to the constitution of an incomes policy (nor, in principle, does it identify the state as a necessary participant in the construction of an incomes policy), but is designed to acknowledge the important role that informal institutions (including social norms and conventions) are also likely to play in any set of arrangements that successfully ameliorates distributional conflict.

Note also that, as will become clear in what follows, incomes policies that conform to the broad definition introduced above can be - and have, in fact, been - either 'cooperative' or 'coercive'. In other words, incomes policies do not always ameliorate distributional conflict in ways that are mutually acceptable to all parties. In this way, the precise structure of an incomes policy can be thought of as codifying the distribution of bargaining power in the economy.

4 Of course, this conventional wisdom owes, in part, to the narrower definition of incomes policies that it adopts, as a result of which incomes policies are identified purely with formal institutions and are thus, by definition, generally conspicuous by their absence. 


\section{Methodology}

As suggested above, and following Setterfield and Cornwall (2002), the basic vision of the economy on which this paper rests involves certain 'fundamental' principles of the inflation process embedded in a historically specific institutional framework that impinges upon the process of aggregate wage and price setting. A fundamental refers to 'a proposition that we take as basic to the functioning of capitalism, regardless of the precise... [inflation] episode that we are dealing with' (Setterfield and Cornwall, 2002: 70). In the current context, our fundamentals can be reduced to the following propositions:

(a) Conflict over the distribution of income is central to the process of inflation. Contrary to the view that inflation is exclusively the product of excess aggregate demand, we regard inflation as the result of the irreconcilable demands of different social groups on real output, inflation being what results when these conflicting claims are expressed in nominal terms, as in a moneyusing economy.

(b) Both the power of workers vis-à-vis the wage bargain and the power of firms vis-à-vis the goods market are incomplete. In other words, neither workers nor firms can fully index their expectations or aspirations into wages and prices.

(c) Workers and firms bargain over the determination of the nominal wage, following which firms set prices (and hence the value of the real wage). This is consistent with the first principles of a money-using economy as articulated by Keynes (1936: ch. 2), and rules out the idea that workers and firms enter into direct negotiations concerning the size of the real wage (as in a barter system).

These fundamentals, together with the institutional framework within which they are embedded, allow us to identify three 'regimes' on which the analysis of inflation can then be based. The wage and price regimes identify the determinants of the rate of growth of nominal wages and prices, respectively, in a manner consistent with the fundamentals of the inflation process identified above. As will become clear in the following section, these regimes can be summarized in terms of a conflicting claims model of inflation. ${ }^{5}$ Finally, the institutional regime is:

a relatively enduring macro-institutional structure within which economic behaviour takes place. It constitutes the 'operating system' that provides the social infrastructure necessary, in an environment of uncertainty and conflict, to create stability, undergird the state of long run expectations, [define and]

5 See, for example, Burdekin and Burkett (1996) and Lavoie (1992: ch. 7) for surveys of the conflicting claims approach. 
reconcile competing distributional demands, and hence facilitate economic activity amongst decentralized decision makers. ${ }^{6}$

(Setterfield and Cornwall, 2002: 71)

In other words, the institutional regime creates 'conditional closure' in an otherwise open economic system (Setterfield, 2003). ${ }^{7}$ Closure is again conditional in the specific sense that it depends on the reproduction over time of a set of relatively enduring - but ultimately transmutable - institutions. Like the institutions from which it derives, of course, conditional closures are also relatively enduring. Hence combination of the wage, price and institutional regimes - which together comprise the macroeconomic regime alluded to earlier - permits identification of actual inflation outcomes, which emerge as relatively enduring, conditional equilibrium values characteristic of a discrete episode of macroeconomic performance. ${ }^{8}$ Once again, the conditionality of these equilibrium values stems from the fact that they are contingent on the reproduction over time of a relatively enduring - but ultimately transmutable institutional regime. ${ }^{9}$

In what lies ahead, we first develop a conflicting claims model of inflation to represent the wage and price regimes described above. We then identify three distinct institutional regimes in the post-war US economy, and show how the use of these institutional regimes to 'calibrate' the wage and price regimes explains the inflation experience of the US economy described in the introduction as three distinct episodes of macroeconomic performance associated with the rise, decline, and rise of successive incomes policies.

\section{Modelling the wage and price regimes: a conflicting-claims model of inflation}

The wage and price regimes described in the previous section are captured by the following equations, which together comprise the basis of a conflicting-claims model of inflation

$$
w=\mu_{1}\left(\omega_{w}-\omega\right)+\mu_{2} q+\mu_{3} p^{e}, 0<\mu_{i}<1 \forall_{i}
$$

6 As will become clear in what follows, the constituents of the institutional regime that are the focus of attention in this particular paper include, inter alia, labour law, the norms and rules of the industrial relations system, and conventions governing the behaviour and interaction of firms in product markets.

7 See also Crotty (1994) on the conceptually similar notion of conditional stability in macro systems.

8 See Setterfield (1997) on the notion of conditional equilibrium, and Chick and Caserta (1997) on the related notion of provisional equilibrium.

9 The blend of formal modelling and institutional detail that ultimately furnishes an explanation of observed macroeconomic outcomes in this approach might be regarded as an analytical institutional economics and/or as a branch of analytical political economy (Dutt, 1994; Setterfield, 2005). The approach certainly has obvious antecedents in the work of the social structure of accumulation and regulation theories (see, for example, Kotz et al., 1994 and Boyer, 1990, respectively), structuralist macroeconomics (see, for example, Taylor, 2004) and the work of post-Keynesians such as Cornwall (1990) and Cornwall and Cornwall (2001). 


$$
p=\varphi\left(\omega-\omega_{F}\right)+w-q, 0<\varphi<1
$$

where $w$ denotes the rate of growth of nominal wages, $\omega_{W}$ is the target wage share of workers, $\omega$ is the actual wage share, $q$ is labour productivity growth, $p^{e}$ and $p$ denote the expected and actual rates of inflation, respectively, and $\omega_{F}$ is the target wage share of firms, where $\omega_{W}>\omega_{F}$ by assumption. Equation (1) represents the wage regime, describing the rate of growth of nominal wages as a function of the difference between workers' target wage share and the actual wage share (the former representing their distributional aspirations), the rate of productivity growth, and expected inflation (both of which, ceteris paribus, will affect the wage share unless the nominal wage is adjusted in compensating fashion). ${ }^{10}$ The parameters $\mu_{i}$ are determined by the relative power of workers vis-à-vis firms in the wage bargain. We need not always observe $\mu_{i}=\mu_{j}$, however, since, for any given degree of bargaining power, workers may expend more or less effort on, for example, ensuring that $w$ responds to $p^{e}$ as opposed to other variables in (1). ${ }^{11}$ Nevertheless, for the sake of simplicity we will assume that $\mu_{i}=$ $\mu_{j}$ for all $i, j$ in what follows, so that we can write the wage regime as

$$
w=\mu\left[\left(\omega_{w}-\omega\right)+q+p^{e}\right]
$$

Note also that

$$
\mu=\mu(U, S), \mu_{U, \mu_{S}}<0
$$

and

$$
\omega_{W}=\omega(U, S, Z), \omega_{U}<0
$$

where $U$ denotes the rate of unemployment, $S$ denotes institutional features of the labour market and industrial relations system that diminish the ability and/or willingness of workers to press for nominal wage increases, ${ }^{12}$ and $Z$ is a vector of other variables that affects workers' perceptions of a fair wage share (including, for example, historical experience). Equation (3) states that the extent to which workers index expected inflation, productivity growth, and disparities between their preferred wage share and the actual wage share into nominal wage growth varies inversely with the rate of unemployment and the institutional determinants

10 This is evident from the definition of the wage share, $\omega=W N / P Q$, where $W$ is the nominal wage, $N$ the level of employment, $P$ the price level, and $Q$ denotes aggregate output. If $P$ rises or $N / Q$ (the reciprocal of the level of labour productivity) falls, $\omega$ will fall unless these changes are offset by a rise in $W$.

11 This is consistent with the notion that workers may pay more or less attention to inflation expectations in the process of wage bargaining, depending on the size of the expected inflation rate. See, for example, Palley (2006) and Akerlof (2002).

12 The value of $S$ will therefore be influenced by such concrete institutions as labour law, the degree to which collective bargaining is centralized, the extent to which consultation is a normal feature of the employment relationship, the extent to which practices such as downsizing, outsourcing or plant relocation are conventional features of firm behaviour, and so forth. 
of the ability and/or willingness of workers to press for nominal wage increases. Equation (4), meanwhile, is based on the work of Setterfield and Lovejoy (2006) who, following Kahneman et al. (1986), postulate that aspirations are influenced by multiple objective 'reference points' based on salient past and present events. In the case of $\omega_{W}$ in equation (4), these reference points include both $U$ and $S$. Hence workers' wage share aspirations are inversely related to the rate of unemployment on the basis of the hypothesis that a paucity of employment opportunities diminishes workers' subjective sense of self-worth. At the same time, $\omega_{W}$ is affected by the institutions that comprise $S$, although the sign of $\omega_{S}$ is ambiguous. This is because the impact of $S$ on worker aspirations will depend upon the character of the precise institutional regime within which the wage and price regimes above are embedded, and thus cannot be determined a priori. ${ }^{13}$ The full significance of equations (3) and (4) will become more evident in Section 4 below.

Equation (2) captures the price regime, describing the rate of inflation as depending upon the rate of growth of unit labour costs $(w-q)$ and the difference between the actual wage share and firms' target wage share. The parameter $\varphi$ is determined by the state of competition in product markets and the corresponding ability of firms to mark up prices in excess of the average costs of production. ${ }^{14}$ Indeed, the price regime in equation (2) is essentially a dynamic version of a standard mark-up pricing equation in which the mark up (and hence $\omega_{F}$ ) is determined by the target rate of return on firms' assets. ${ }^{15}$ To see this, note that by definition

$$
r=\frac{(1-\omega) u}{v}
$$

where $r$ is the rate of profit, $(1-\omega)$ is the profit share, $u$ is the rate of capacity utilization, and $v$ is the fixed capital-output ratio derived from the production technology. It follows that

$$
r^{T}=\frac{\left(1-\omega_{F}\right) u_{n}}{v}
$$

13 Particularly important is the extent to which the institutional regime encourages workers to perceive the employment relationship as either one of 'social partnership' or 'employer unilateralism' - which will either raise or lower workers' subjective sense of self-worth, respectively. See Setterfield and Lovejoy (2006) for further discussion of the determinants of workers' aspirations and for a fuller account of the ambiguous sign of $\omega_{S}$.

14 In this way, $\varphi$ is analogous to Kalecki's (1971) degree of monopoly, and will therefore be influenced by factors such as the concentration of domestic markets, overhead costs, the price elasticity of demand for final output and the amount of international competition faced by firms. Some of these same factors may influence the target rate of return on firms' assets and hence, as demonstrated immediately below, the value of $\omega_{F}$.

15 See Lee (1998: 206) for discussion of the prevalence of target rate of return pricing amongst business enterprises. 
or

$$
\omega_{F}=1-\frac{r^{T} v}{u_{n}}
$$

where $r^{T}$ denotes the target rate of return established by firms and $u_{n}$ is the normal rate of capacity utilization at which this target rate of return is calculated.

It is worth remarking at this point on the fidelity of the wage and price regimes above to the fundamentals identified in the previous section. Hence note that distributional conflict is made central to the inflation process by the dependence of $w$ and $p$ on $\omega_{W}$ and $\omega_{F}$, where $\omega_{W}>\omega_{F}$. Meanwhile, the assumptions that $\mu$, $\varphi<1$ are consistent with the claim that workers' power vis-à-vis the wage bargain and firms' power vis-à-vis the goods market is incomplete; neither workers nor firms are capable of fully indexing all of the determinants of $w$ or $p$ into nominal wage growth or price inflation, respectively. Finally, the principle that workers and firms bargain over the nominal wage, with the real wage determined only once prices have been set in the goods market, is captured by the facts that (1a) explicitly describes a nominal wage setting process and that despite the fact that nominal wage growth is influenced by productivity growth and expected inflation in (1a), the actual rate of growth of the real wage is always determined in $(2)$ as

$$
w-p=-\varphi\left(\omega-\omega_{F}\right)+q
$$

As discussed in the previous section, the specific conditional equilibrium outcomes that will emerge from the model under construction here cannot be identified unless we first specify the institutional regime within which the wage and price regimes are embedded and which, by determining the values of variables such as $S$, creates conditional closure within the model. Nevertheless, it is possible at this stage to identify certain general conditions necessary for any specific conditional equilibrium to emerge within this model, and to explore the consequences of these conditions for the wage and price regimes described above. These conditions include the realization of inflation expectations $\left(p=p^{e}\right)$ and constancy of the wage share over time (which, from the definition of the wage share, implies that $p=w-q)$. Combining both of these general equilibrium conditions with (1a) yields

$$
w=\frac{\mu}{1-\mu}\left(\omega_{W}-\omega\right)
$$

whilst combining the second with equation (2) yields

$$
\omega=\omega_{F}
$$

We can now utilize the information in (5) and (6) to deduce certain general properties that will be characteristic of any specific conditional equilibrium values 
of $w, p$, and $\omega$ that we subsequently derive. Hence denoting an equilibrium value with an asterisk, it follows directly from (6) that

$$
\omega^{*}=\omega_{F}
$$

In other words, the equilibrium value of $\omega$ is ultimately determined in the goods market and by the aspirations of firms - independently of $\mu$ and $\omega_{W}$ (the bargaining power and aspirations of workers) in the wage bargain. ${ }^{16}$ Meanwhile, substituting (7) into (5) we arrive at

$$
w^{*}=\frac{\mu}{1-\mu}\left(\omega_{W}-\omega_{F}\right)
$$

from which, given the general equilibrium condition $p=w-q$, it follows that

$$
p^{*}=\frac{\mu}{1-\mu}\left(\omega_{W}-\omega_{F}\right)-\bar{q}
$$

where $\bar{q}$ denotes the (assumed given) trend rate of productivity growth. ${ }^{17}$ Equations (8) and (9) describe the equilibrium rates of growth of nominal wages and prices as functions of workers' bargaining power and the 'aspiration gap' $\omega_{W}-\omega_{F}$ (the difference between workers' and firms' wage share targets).

Two further key results emerge from equations (8) and (9). The first is that $w^{*}$ and $p^{*}$ are both increasing in $\mu$. To see this, note that

$$
\frac{\partial w^{*}}{\partial \mu}=\frac{\partial p^{*}}{\partial \mu}=\frac{\omega_{W}-\omega_{F}}{(1-\mu)^{2}}>0
$$

Other things being equal, the equilibrium rates of wage and price inflation will vary directly with the bargaining power of workers. Second, both $w^{*}$ and $p^{*}$ are increasing in the 'aspiration gap' $\omega_{W}-\omega_{F}$. Hence

$$
\frac{\partial w^{*}}{\partial\left(\omega_{W}-\omega_{F}\right)}=\frac{\partial p^{*}}{\partial\left(\omega_{W}-\omega_{F}\right)}=\frac{\mu}{1-\mu}>0
$$

Other things being equal, any increase in $\omega_{W}$ or any decrease in $\omega_{F}$ will raise the equilibrium rates of wage and price inflation, and vice versa. ${ }^{18}$

16 There may, in principle, be circumstances in which $\mu$ and $\omega_{W}$ affect $\omega_{F}$ (i.e., $\omega_{F}$ may not ultimately be set autonomously by firms) - on which, see Section 4 below. But this interaction is not systematic in the model developed above.

17 It is possible, of course, that the distribution of income will interact with the rate of productivity growth. For example, a wage share that falls far short of $\omega_{W}$ may be perceived as unjust by workers and trigger adverse efficiency wage effects. Alternatively, the equilibrium wage share may influence the nature and extent of technical progress by placing more or less pressure on firms to innovate in order to raise profits. Finally, in a demand-led growth environment, changes in the wage share may affect the rate of growth of real output and hence the rate of growth of productivity via the Verdoorn Law. By treating productivity growth as given, we are abstracting from these plausible interactions for the sake of simplicity.

18 The fact that $p^{*}$ is sensitive to $\omega_{F}$ demonstrates that inflation can be firm-induced in the model above. For example, if an increase in commodity prices were to squeeze net profit margins, and if this led firms to 
Figure 1. Conflicting-claims inflation

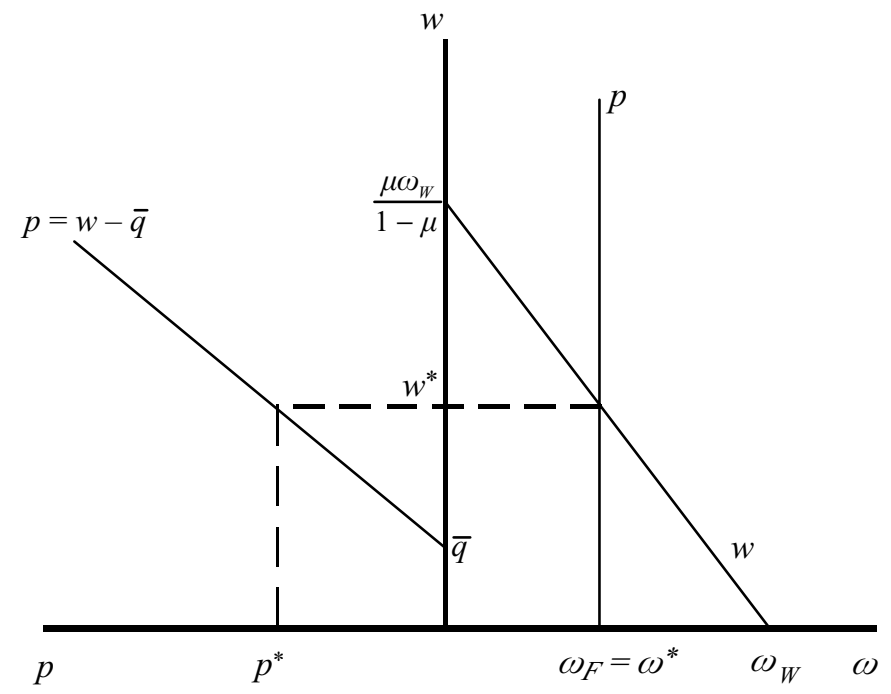

The wage and price regimes in equations (5) and (6) together with the general equilibrium condition $p=w-q$ are illustrated in Figure 1, which depicts an imagined conditional equilibrium configuration corresponding to some (unspecified) institutional regime. ${ }^{19}$

Having thus specified wage and price regimes consistent with the fundamentals identified in the previous section, and having identified certain general equilibrium properties of these regimes, we are now in a position to 'calibrate' the resulting model using information about institutions. This will enable us to show how changes in the institutional regime of the US economy over the past 50 years have resulted in the evolution of the US economy through several successive episodes of macroeconomic performance - an evolution that, in terms of its impact on the variables of interest here, can ultimately be interpreted in terms of the rise, decline, and rise of successive incomes policies. It is to this task that we now turn.

raise their target rate of return $r^{T}$ in an effort to restore net profitability, the result would be an increase in $\omega_{F}$ (appealing to the dependence of $\omega_{F}$ on $r^{T}$ demonstrated earlier) and hence, via (9), $p^{*}$.

19 Following Kregel (1976), Figure 1 simply assumes a given value of $S$, making no effort to explain the value of this variable and 'locking up without ignoring' its capacity to change over time. This creates an 'artificial' closure designed to highlight features of our model associated with its fundamentals, rather than with the precise institutional regime within which these are, at any point in time, embedded. Notice, however, that the wage and price regimes described in this section and summarized in Figure 1 inevitably pre-empt the role of institutions in the model developed here. For example, the pricing behaviour assumed to justify the form of the price regime in equation (2) is, itself, properly understood as a conventional rather than 'natural' feature of the economy. 
Table 1. US macroeconomic performance since 1960

\begin{tabular}{lcccc}
\hline \hline & $1960-73$ & $1974-79$ & $1980-89$ & $1990-2000$ \\
\hline INFLATION $^{1}$ & 3.1 & 9.6 & 5.6 & 3.1 \\
WAGE SHARE $^{2}$ & 57.4 & 59.1 & 58.4 & 57.7 \\
PRODUCTIVITY GROWTH $^{3}$ & 3.1 & 1.3 & 1.6 & 2.0 \\
UNEMPLOYMENT $^{4}$ & 4.9 & 6.8 & 7.3 & 5.6 \\
WORKER INSECURITY $^{5}$ & $\mathrm{~N} / \mathrm{A}$ & 0.21 & 0.57 & 0.82 \\
\hline \hline
\end{tabular}

Notes: 1. Percentage rate of change of the CPI, all items, Economic Report of the President, 2004: 357.

2. Compensation of employees as a percentage of Gross Domestic Income, Bureau of Economic Analysis National and Income and Product Accounts, Table 1.11 (www.bea.doc.gov)

3. Percentage rate of change of output per hour of all persons, business sector, Economic Report of the President, 2004: 343.

4. Unemployed persons as a percentage of the civilian labour force, Economic Report of the President, 2004: 334 .

5. Index of worker insecurity (Setterfield, 2005).

\section{The rise, decline and rise of incomes policies in the US}

Table 1 presents the stylized facts of US macroeconomic performance over the past four decades. The first row of Table 1 clearly illustrates the 'low-highlow' evolution of inflation since 1960, two episodes of low inflation (1960-73 and 1990-2000) separated by the high inflation interlude of the 1974-89 period. Table 1 also reveals the extent to which this episodic behaviour of inflation has been accompanied by similarly episodic behaviour in other macroeconomic variables. Hence roughly comparable values of the wage share, rate of productivity growth, and unemployment rate during the periods 196073 and 1990-2000 are separated by a rise in the wage share, a marked decline in the rate of productivity growth and a marked increase in the unemployment rate $1974-89 .{ }^{20}$ In this section, we will argue that the stylized facts in Table 1 can be understood as a series of episodic macroeconomic outcomes associated with three qualitatively different macroeconomic regimes, the defining feature of each of which has been the institutional regime within which the wage and price regimes outlined in Section 3 were embedded.

A common theme in political economy identifies the post-war Golden Age (1948-73) with a historic compromise between capital and labour, as a result of which the distributional goals of workers and firms were (at least partially) reconciled (Bowles et al., 1990; Cornwall, 1990; Glyn et al., 1990; Cornwall and Cornwall, 2001). This 'value sharing' norm of distributive justice is understood to have been codified in the form of 'social bargains', under the terms of

20 Note that from 1995-2000, the average annual rate of unemployment in the US fell to $4.8 \%$, slightly below its 1960-73 value. The annual average rate of productivity growth rose slightly to $2.3 \%$ during the same period - considerably below its 1960-73 value, but comparable to its value of $2.5 \%$ during the Golden Age as a whole (Maddison, 1991: 51).

We return to discuss the significance of the fifth row of Table 1 below. 
which firms retained the 'right to manage' in return for commitment to a high and stable wage share of income and annual growth in real earnings. The social bargains were not uniform across capitalist economies, being more highly developed in northern Europe and Japan than in the Anglo-Saxon economies (Cornwall, 1990). ${ }^{21}$ Hence the US achieved only a 'limited capitallabour accord' (Bowles et al., 1990) during the Golden Age. Nevertheless, by better reconciling the distributional conflict at the heart of the inflation process, social bargains - even in the limited form found in the US - had a beneficial impact on the unemployment and growth performances of the advanced capitalist economies (Bowles et al., 1990; Cornwall, 1990; Glyn et al., 1990; Cornwall and Cornwall, 2001; Setterfield and Cornwall, 2002). In keeping with this theme, the position adopted here is that the limited capital-labour accord created an institutional regime that explains the precise constellation of macroeconomic outcomes in the first column of Table 1 , as a discrete episode of US macroeconomic performance characterized by high growth, low unemployment, and low rates of inflation. More precisely, the limited capitallabour accord in the US constituted an incomes policy in the sense defined earlier, raising the value of $S$ in equation (3) by reducing the willingness of workers to press for nominal wage increases purely on the basis of the market power vested in them by a low rate of unemployment. ${ }^{22}$ This alleviated the inflation constraint on the US economy (the need to sacrifice growth and employment by raising $U$ in order to lower $\mu$ and $\omega_{W}$ in equations (3) and (4), and hence reduce inflation in equation (9)), facilitating, in turn, the reconciliation of rapid growth and low unemployment with low rates of inflation precisely the triad observed in the first column of Table 1.

After 1968, however, the social bargains described above began to unravel and - along with the value-sharing norm of distributive justice on which they were based - had broken down altogether by 1973 (Bowles et al., 1990; Cornwall, 1990; Cornwall and Cornwall, 2001). Rather than being based on compromise and reconciliation, the early 1970s witnessed the emergence of a 'market power' approach to industrial relations, the embodiment of a 'winner take all' norm of distributive justice. These developments were associated in the first instance with 'aspiration inflation' on the part of labour, emanating both from materially secure workers who had grown accustomed to the experience of full employment and steadily rising real incomes during the Golden Age (Cornwall, 1990), and from 'new' workers (including women and minorities) who had not benefitted from the spoils of the post-war social bargains

21 According to Cornwall (1990), this lack of uniformity explains differences in macroeconomic performance amongst advanced capitalist economies during the Golden Age.

22 Setterfield and Lovejoy (2006) argue that the participatory and conciliatory nature of social bargains is such that we can expect to observe $\omega_{S}>0$ in equation (4). Their empirical evidence, however, is consistent with the view that the net effect of social bargains on inflation (given that $\mu_{S}<0$ in (3)) was negative. 
Figure 2. The breakdown of social bargains

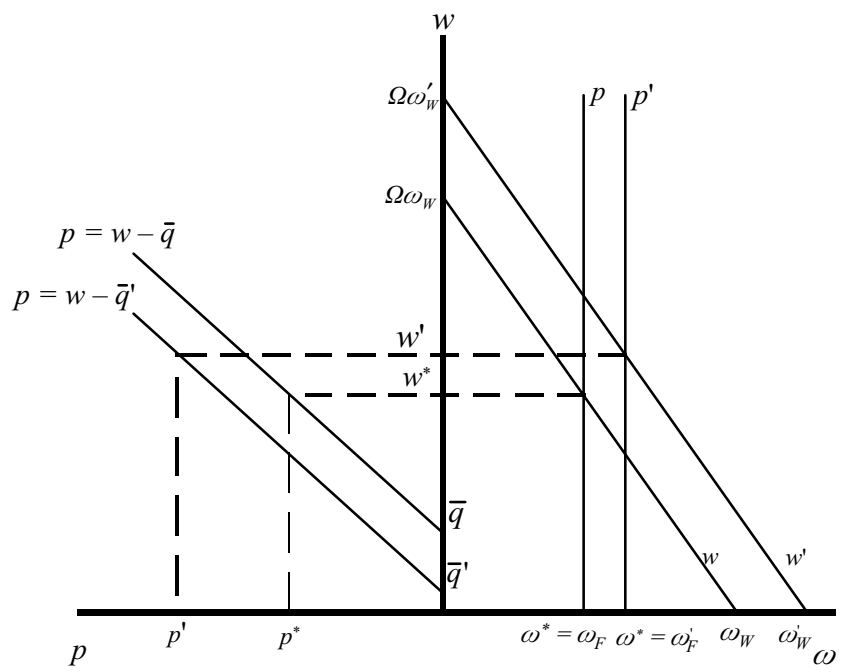

Note: $\Omega=\frac{\mu}{1-\mu}$.

(Bowles et al., 1990). ${ }^{23,24}$ These institutional changes - together with their implications for inflation - are illustrated in Figure 2. Replicating the configuration illustrated in Figure 1 and treating this as a stylized representation of the Golden Age macroeconomic regime, Figure 2 then shows an increase in the target wage share of workers (from $\omega_{W}$ to $\omega_{W}^{\prime}$ ) consistent with the aspiration inflation described above. Other things being equal, and in line with equation (11), this worsened inflationary pressures resulting from conflict over the distribution of income. However, and again in a manner congruent with equation (11), Figure 2 shows these inflationary pressures being moderated somewhat by a discrete increase in the target wage share of firms (from $\omega_{F}$

23 According to Bowles et al. (1990: 67-69), income and employment disparities between white males on one hand, and women and racial minorities on the other, widened considerably in the US from 194866. These disparities, they argue, fueled the civil rights and women's movements during the 1960s and had a direct effect on the subsequent legislative attention paid to issues such as affirmative action. In keeping with equation (4), we posit that these latter developments - as a component of the vector $Z$ - enhanced the subjective sense of self-worth of women and minority workers, raising their income share aspirations. Note that since $\omega_{W}=\omega_{M}+\omega_{W M}$, where $\omega_{M}$ is the target income share of white male workers and $\omega_{W M}$ is the target income share of women and minorities, then ceteris paribus, any increase in $\omega_{W M}$ will raise $\omega_{W}$. If an increase in $\omega_{W M}$ also triggers intra-class conflict, causing $\omega_{M}$ to rise as white male workers seek to preserve their share of total wage income, then there will be a second, indirect, effect of any increase in $\omega_{W M}$ on $\omega_{W}$.

24 As will become clear in what follows, capital and the state were quick to respond in kind to this aspiration inflation and its consequences. Indeed, their reactions have become the enduring hallmark of the post-1973 'winner take all' norm of distributive justice and attendant 'market power' approach to addressing the conflicting distributional goals of workers and firms. 
to $\left.\omega_{F}^{\prime}\right)$. The hypothesis here is that this development was related in the first instance to the increased international competition faced by US firms by the end of the 1960s, the most obvious manifestation of which was the disappearance by the early 1970 s of the US trade surplus. ${ }^{25}$ This resulted in a second important institutional change - a decrease in the value of $\varphi$ (US firms 'degree of monopoly') in equation (2). Recall that $\varphi$ itself has no systematic impact on the equilibrium inflation or distributional outcomes in equations (7)-(9). However, the discretionary increase in firms' target wage share depicted in Figure 2 is entertained here as being the result of particular historical circumstances specifically, the combination of pressures on firms emanating from product markets (as captured by the diminution of their 'degree of monopoly', $\varphi$ ) resulting in a need to limit price increases, even as the rate of growth of unit labour costs was increasing as a result of workers' rising aspirations and a slowdown in the trend rate of productivity growth. ${ }^{26}$ As shown in Figure 2, the initial combined effect of the new 'market power' institutional regime that emerged from the breakdown of the post-war social bargains and the fundamentals embodied in the wage and price regimes was thus a higher wage share and a higher rate of inflation - the latter exacerbated by the post- 1973 productivity slowdown. These outcomes are clearly evident in the data in the second column of Table 1.

Although Figure 2 characterizes the 1970s as a conditional equilibrium resulting from the combination of a particular institutional regime with the wage and price regimes outlined in Section 3, it must be noted that this conditional equilibrium is not a 'fully adjusted' position. This is because, as a result of the specific historical conditions described above, it involves $\omega^{*}=\omega_{F}^{\prime}>\omega_{F}$, where the latter denotes the wage share that (other things being equal) is uniquely consistent with firms' target rate of return, $r^{T} \cdot{ }^{27}$ Firms thus have an incentive to

25 The US balance of trade, having been permanently in surplus since the end of World War II, dwindled during the late 1960s and has been more or less permanently in deficit since 1971 .

26 This productivity slowdown is clearly shown in the second and third columns of Table 1 , and its inflationary implications are illustrated in Figure 2, wherein - consistent with equation (9) - a reduction in the trend rate of productivity growth results in a higher rate of inflation associated with any given rate of growth of nominal wages. The post-1973 productivity slowdown is taken as given in the discussion in this paper. See, however, Bowles et al. (1990) and Setterfield and Cornwall (2002) for attempts to explain the productivity slowdown in terms of much the same institutional changes that are the focus of attention above.

27 In terms of the relationship between the rate of profit and the wage share discussed in the previous section, in Figure 2 we have

$$
r^{*}=\frac{\left(1-\omega^{*}\right) u_{n}}{v}=\frac{\left(1-\omega_{F}^{\prime}\right) u_{n}}{v}<\frac{\left(1-\omega_{F}\right) u_{n}}{v}=r^{T}
$$

(Note that, for the sake of simplicity, we are overlooking here any possible impact of the wage share on the rate of capacity utilization and hence the realized rate of profit that might eliminate the incongruity between the actual and target rates of return. Even were we to allow for such effects, the notion that Figure 2 illustrates a less than fully adjusted position might still be justified if firms care innately about realizing their target wage share on the basis of a sense of distributive justice.) In effect, the equilibrium wage share (and hence profit rate) outcome in Figure 2 is based on the 'transitory' price regime

$$
p=\varphi_{1}\left(\omega-\omega_{F}\right)+\varphi_{2}(w-q)
$$


seek further changes to the configuration of the economy depicted in Figure 2 in an effort to re-establish a wage share consistent with their target rate of return.

This brings us to the reaction of firms - and the state - to the aspiration inflation with which we commenced our discussion of the post-1973 period. One widely documented aspect of this response was that of the state, which initially took the form of restrictive macroeconomic policies (Bowles et al., 1990; Cornwall, 1990; Cornwall and Cornwall, 2001; Epstein and Schor, 1990). This response was designed to raise the rate of unemployment and thus (per equations (3), (4), (10), and (11)) diminish inflation by lowering the bargaining power and wage-share aspirations of workers. In view of what was said above about the conjunction of historical circumstances that gave rise to the increase in the target wage share of firms depicted in Figure 2, it is to be expected that these developments would have alleviated the pressure on firms to keep the target wage share as high as $\omega_{F}^{\prime}$. The third column of Table 1 is consistent with the workings out of this policy response during the 1980s. In particular, it draws attention to the combination of rising unemployment (which actually began in the 1970s) coupled with falling inflation and a falling wage share of income. However, Table 1 suggests that the restrictive macroeconomic policies pursued during the 1970s and 1980s were only partially successful as a response to the post-1973 macroeconomic regime depicted in Figure 2. In the first case, it shows that the wage share remained high - above the 1960-73 value associated with a fully adjusted conditional equilibrium. Second, the pursuit of restrictive policies involved a macroeconomic trade-off, in which real macroeconomic performance was sacrificed in order to alleviate inflationary pressures and relieve the profit squeeze on US firms. Hence Table 1 reveals the costs of restrictive macroeconomic policies to have been a sharp increase in unemployment to almost $150 \%$ of its 1960-73 value during the 1980 s. $^{28}$

This leads us to the second aspect of the corporate/state response to the macroeconomic regime of the 1970s, which is evident in the last row of Table 1: a series of initiatives designed to raise the value of $S$ in equations (3) and (4) and thus reduce the willingness and ability of workers to press for nominal wage increases by increasing worker income and employment insecurity. This strategy has been corporate-led, and has involved changing the conventions of the employment relation in order to diminish both the bargaining power and the aspirations of workers. ${ }^{29}$ It has included (inter alia) deunionization initiatives, increases in corporate downsizing exercises, plant relocation, and increases in

where $\varphi_{2}<1$ captures the inability of firms to fully index price inflation to the rate of growth of unit labour costs under the historically specific conditions prevalent during the early 1970 s.

28 See Cornwall and Cornwall (2001) and Setterfield and Cornwall (2002) for the argument that depressed aggregate demand conditions also contributed to the continued poor performance of productivity growth that is evident in the third column of Table 1.

29 According to Setterfield and Lovejoy (2006), the adversarial and confrontational nature of corporate contributions to the post-1973 'market power' institutional regime are such that we can expect to observe $\omega_{S}<0$ in equation (4). 
the quantity of non-standard (part-time and temporary) work, in the pursuit of some of which corporations have been aided by changes in formal institutions brought about by the actions of the state. Hence changes in US labour law created a legal environment that made it easier for firms to engage in deunionization initiatives during the 1980s (Block et al., 1996: 28-33), with the result that union membership in the US has since fallen steadily from over $25 \%$ of private-sector employees during the mid 1970s to barely $10 \%$ by the mid-1990s (Palley, 1998: 32 ). At the same time, periodic downsizing exercises - which create a threat to workers' employment and income security regardless of general economic performance - have become the norm. Osterman (1999:38-40) shows that by the mid-1990s, the number of layoffs in the US accounted for by 'structural change' surpassed the number due to poor firm performance. Similarly - as first discussed by Bluestone and Harrison (1982) - plant relocation has become an omnipresent threat. Between 1967 and 1991, the share of manufacturing employment in the 'rust belt' states of the US fell from $48.6 \%$ to $36.2 \%$, the share of states in the South and West increasing from $37.0 \%$ to $50.2 \%$ over the same period (Crandall, 1993: 12). Apart from its contribution to the process of deunionization reported above, the extent of this relocation - coupled with its internationalization in the age of multinational corporations - has created a credible threat that both directly reduces the security of workers and indirectly reduces this security by diminishing the efficacy of strike activity and union organizing drives (Palley, 1998: 3435; Bronfenbrenner, 2000). ${ }^{30}$ Finally, increases in non-standard employment arrangements have reduced the employment security of those desirous of year round, full-time work, and who now face a reduced likelihood of obtaining such work in the event of dismissal from their current employment (Osterman, 1999: 54-60, 85-88). These developments are captured by the monotonic rise of the index of worker insecurity reported in the last row of Table $1 .{ }^{31}$

In short, in response to the macroeconomic regime prevalent in the US during the 1970s and 1980s, there has occurred a constellation of institutional changes that have diminished worker employment and income security independently of the performance of the aggregate labour market, as measured by the rate of unemployment. The consequences of this are illustrated in Figure 3 below, and are also evident in the data in the final column of Table 1. Figure 3 first shows a decline in both the bargaining power (from $\mu$ to $\mu^{\prime}$ ) and wage share aspirations (from $\omega_{W}^{\prime}$ to $\omega_{W}^{\prime \prime}$ ) of workers as a result of the institutional changes detailed above, which are manifest in an increase in $S$ in equations (3) and (4). ${ }^{32}$ Consistent with equations (10) and (11), this will reduce inflationary pressures,

30 See also Dreher and Gaston (2005) for evidence of the link between globalization and deunionization.

31 This index is the unweighted average of the transformed values of several variables that either reflect or affect worker insecurity, including trade union membership, the extent of part time employment, and the number of work stoppages per annum. See Setterfield (2005: 167, 170-71) for further discussion of both the components and calculation of the index of worker insecurity reported in Table 1.

32 Recall that the particular rise in $S$ contemplated here is consistent with $\omega_{S}^{\prime}<0$ in equation (4). 
Figure 3. An incomes policy based on fear

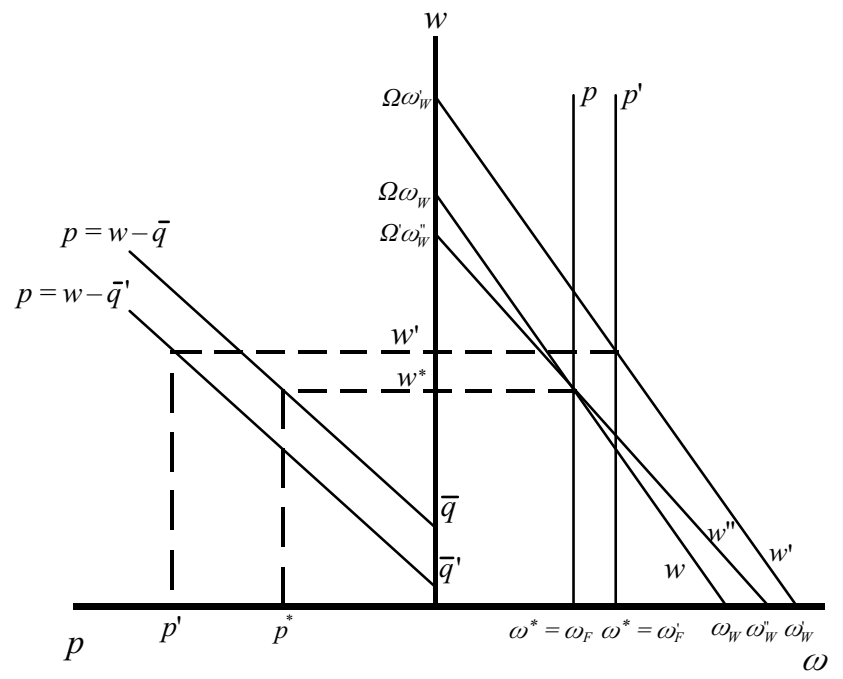

Note: $\Omega^{\prime}=\frac{\mu^{\prime}}{1-\mu^{\prime}}<\frac{\mu}{1-\mu}=\Omega$.

at the same time alleviating the need for firms to maintain an elevated target wage share. This latter development is captured by the fall in firms' target wage share from $\omega_{F}^{\prime}$ to $\omega_{F}$ in Figure 3, making the conditional equilibrium depicted in Figure 3 a fully adjusted position. ${ }^{33}$ The result of these developments, as illustrated in Figure 3, is a fall in both the rate of wage inflation and the wage share of income, the former resulting in a decline in price inflation enhanced by the improvement of trend productivity growth to something like its value during the Golden Age. The upshot of all this is the restoration of a rate of inflation and distribution of income comparable to those achieved during the Golden Age, all without sacrificing employment. More precisely, the contention here is that by the 1990s, the institutional regime of the US economy again involved an incomes policy in the sense defined earlier, which operated by raising the value of $S$ in equations (3) and (4) and thus reducing both the willingness and ability of workers to press for nominal wage increases, regardless of the market power seemingly vested in them by a low rate of unemployment. This incomes policy again alleviated the inflation constraint on the US economy - the need to sacrifice growth and employment in order to raise $U$, lower $\mu$ and $\omega_{W}$ in

33 Referring back to the 'transitory' price regime $p=\varphi_{1}\left(\omega-\omega_{F}\right)+\varphi_{2}(w-q)$ used to discuss outcomes in Figure 2 above, we now have $\varphi_{2}=1$ again as a result of firms having successfully 'passed on' the pressures of globalized commodity markets to workers. Essentially what we are postulating is that globalization has an initial effect on firms (captured by $\varphi_{2}<1$ in the 'transitory' price regime) that does not persist: as firms (aided by the state) find ways of reducing $\mu$ and/or $\omega_{W}$ in the wage regime, this so moderates unit labour cost growth $(w-q)$ as to permit a return to the full indexing of the latter into $p$ (i.e., $\varphi_{2}=1$ ). 
equations (3) and (4), and hence reduce inflation in (9) - facilitating, in turn, the reconciliation of rapid growth and low unemployment with low rates of inflation and a distribution of income acceptable to firms. These are, of course, precisely the macroeconomic outcomes observed in the final column of Table 1.

\section{Conclusion}

According to the vision articulated in this paper, at any point in time we can conceive of the macroeconomic 'data generating process' as consisting of a set of fundamentals embedded in a relatively enduring institutional framework - the latter subject to discontinuous change over time, partly in response to the very conditional equilibrium macroeconomic outcomes to which it gives rise. This furnishes a conception of the long run as comprising an evolutionary sequence of discrete 'episodes' of macroeconomic performance (the defining structural characteristic of each episode being a specific institutional framework), rather than as a path-independent trend from which there are but temporary departures caused by independent and transitory shocks.

In this paper, the vision of macroeconomics described above has been used to create a model of inflation comprising wage and price regimes consistent with a conflicting claims view of the inflation process. This model is rendered conditionally closed (resulting in a conditional equilibrium solution) by the identification of the precise institutional regime within which, during some particular interval of historical time, the wage and price regimes are embedded. The result is a tripartite periodization of the US economy into three distinct 'episodes' of macroeconomic performance (1960-73, 1974-89, 1990-2000) based on three distinct institutional regimes. Crucial to the thesis advanced at the start of this paper, the first and third of these institutional regimes have been identified as featuring incomes policies - formal and/or informal institutions that frame and mediate aggregate wage and price setting behaviour in such a way as to reduce conflict over income shares and better reconcile conflicting income claims - that have given rise to similar macroeconomic outcomes and which, in conjunction with the institutional features of the intervening episode, help to explain the recent evolution of the US economy through successive episodes of low, high, and low inflation. The incomes policies that 'bookend' the past 50 years of US macroeconomic performance differ profoundly in their structural features. Hence, whilst the limited capital-labour accord was a model of cooperation and conciliation in which conflict was ameliorated through consensus building, the constellation of institutions identified with the most recent institutional regime comprise an 'incomes policy based on fear' (Cornwall, 1990) - a model of domination in which conflict is ameliorated essentially by means of coercion and in which the costs of better reconciling distributional conflict and reducing inflationary pressures fall squarely on the shoulders of workers. Nevertheless, both achieve - albeit in radically different ways - the 
reduction of distributional conflict characteristic of incomes policies and it is because of this that the US economy can ultimately be said to have experienced the rise, decline, and rise of incomes policies over the past 50 years.

\section{References}

Akerlof, G. (2002), 'Behavioral macroeconomics and macroeconomic behavior', American Economic Review, 92: 411-433.

Block, R. N., J. Beck, and D. H. Kruger (1996), Labor Law, Industrial Relations and Employee Choice, Kalamazoo, MI: W. E. Upjohn Institute for Employment Research.

Blueston, B. and B. Harrison (1982), The Deindustrialization of America: Plant Closings, Community Abandonment, and the Dismantling of Basic Industry, New York: Basic Books.

Bowles, S., D. M. Gordon, and T. E. Weisskopf (1990), After the Waste Land, Armonk, NY: T. E. Sharpe.

Boyer, R. (1990), The Regulation School: A Critical Introduction, New York: Columbia University Press.

Bronfenbrenner, K. (2000), 'Uneasy terrain: the impact of capital mobility on workers, wages and union organizing', Report to the US Trade Deficit Review Commission.

Burdekin, R. C. K. and P. Burkett (1996), Distributional Conflict and Inflation: Theoretical and Historical Perspectives, London: Macmillan.

Chick, V. and M. Caserta (1997), 'Provisional equilibrium and macroeconomic theory', in P. Arestis, G. Palma, and M. Sawyer (eds), Markets, Unemployment and Economic Policy: Essays in Honour of Geoff Harcourt, Vol. II, London: Routledge.

Clarida, R., J. Gali, and M. Gertler (1999), 'The science of monetary policy: a new Keynesian perspective', Journal of Economic Literature, 37: 1661-1707.

Clarida, R., J. Gali, and M. Gertler (2000), 'Monetary policy rules and macroeconomic stability: evidence and some theory', Quarterly Journal of Economics, 115: 147180.

Cornwall, J. (1990), The Theory of Economic Breakdown: An Institutional-Analytical Approach, Oxford: Basil Blackwell.

Cornwall, J. and W. Cornwall (2001), Capitalist Development in the Twentieth Century, Cambridge: Cambridge University Press.

Crandall, R. W. (1993), Manufacturing on the Move, Washington, DC: Brookings Institution.

Crotty, J. (1994), 'Are Keynesian uncertainty and macrotheory compatible? Conventional decision making, institutional structures and conditional stability in Keynesian macromodels', in G. Dymski and R. Pollin (eds), New Perspectives in Monetary Macroeconomics, Ann Arbor: University of Michigan Press.

Collard, F. and H. Dellas (2004), 'The great inflation of the 1970s', Board of Governors of the Federal Reserve System International Finance Discussion Paper No. 799

Dreher, A. and N. Gaston (2005), 'Has globalisation really had no effect on unions?' Swiss Institute for Business Cycle Research, Working Paper No. 110

Dutt, A. K. (1994), 'Analytical political economy: an introduction', in A. K. Dutt (ed.), New Directions in Analytical Political Economy, Aldershot: Edward Elgar.

Epstein, G. and J. Schor (1990), 'Macropolicy in the rise and fall of the Golden Age', in S. A. Marglin and J. B. Schor (eds), The Golden Age of Capitalism: Reinterpreting the Post War Experience, Oxford: Oxford University Press. 
Glyn, A. A. Hughes A. Lipietz, and A. Singh (1990), 'The rise and fall of the Golden Age', in S. A. Marglin and J. B. Schor (eds), The Golden Age of Capitalism: Reinterpreting the Post War Experience, Oxford: Oxford University Press.

Hunt, A. (2002), 'Incomes policy', in B. Snowdon and H. R. Vane (eds), An Encyclopedia of Macroeconomics, Cheltenham: Edward Elgar.

Kahneman, D. J. L. Knetsch, and R. Thaler (1986), 'Fairness as a constraint on profit seeking: entitlements in the market', American Economic Review, 76: 728-741.

Kalecki, M. (1971), 'Costs and prices', in Selected Essays on the Dynamics of the Capitalist Economy, Cambridge: Cambridge University Press.

Kotz, D. M., T. McDonough, and M. Reich (eds), (1994), Social Structures of Accumulation: The Political Economy of Growth and Crisis, Cambridge: Cambridge University Press.

Kregel, J. (1976), 'Economic methodology in the face of uncertainty', Economic Journal, 86: 209-225.

Lavoie, M. (1992), Foundations of Post-Keynesian Economic Analysis, Aldershot: Edward Elgar.

Lee, F. (1998), Post-Keynesian Pricing Theory, Cambridge: Cambridge University Press.

Maddison, A. (1991), Dynamic Forces in Capitalist Development: A Long-Run Comparative View, Oxford: Oxford University Press.

Marglin S. A and J. B. Schor (eds) (1990), The Golden Age of Capitalism: Reinterpreting the Post War Experience, Oxford: Oxford University Press.

Orphanides, A. and J. C. Williams (2004), 'The decline of activist stabilization policy: natural rate misperceptions, learning and expectations', European Central Bank Working Paper No. 337.

Osterman, P. (1999), Securing Prosperity: The American Labor Market: How It Has Changed and What to Do about It, Princeton, NJ: Princeton University Press.

Palley, T. I. (1998), Plenty of Nothing: The Downsizing of the American Dream and the Case for Structural Keynesianism, Princeton, NJ: Princeton University Press.

Palley, T. I. (2006), 'A Post Keynesian framework for monetary policy: why interest rate operating procedures are not enough', in L. P. Rochon and C. Gnos (eds), Economic Policies: Perspectives from the Keynesian Heterodoxy, Cheltenham: Edward Elgar.

Setterfield, M. (1997), 'Should economists dispense with the notion of equilibrium?', Journal of Post Keynesian Economics, 20: 47-76.

Setterfield, M. (2003), 'Critical realism and formal modelling: incompatible bedfellows?', in P. Downward (ed.), Applied Economics and the Critical Realist Critique, London: Routledge.

Setterfield, M. (2005), 'Interactions in analytical political economy: an introduction', in M. Setterfield (ed.), Interactions in Analytical Political Economy: Theory, Policy and Applications, Armonk, NY: M. E. Sharpe.

Setterfield, M. and J. Cornwall (2002), 'A neo-Kaldorian perspective on the rise and decline of the Golden Age', in M. A. Setterfield (ed.), The Economics of Demand-Led Growth: Challenging the Supply Side Vision of the Long Run, Cheltenham: Edward Elgar.

Setterfield, M. and T. Lovejoy (2006), 'Aspirations, bargaining power and macroeconomic performance', Journal of Post Keynesian Economics, 29: 117-148.

Taylor, L. (2004), Reconstructing Macroeconomics: Structuralist Proposals and Critiques of the Mainstream, Cambridge, MA: Harvard University Press. 